\title{
Splenic infarct presenting as acute chest pain
}

\author{
Stella Pak ${ }^{1 *}$ and Yusuf Askaroglu $\mathrm{AS}^{2}$ \\ ${ }^{1}$ Department of Medicine, Kettering Medical Center, Kettering, Ohio, USA \\ ${ }^{2}$ Department of Medicine, Boonshoft School of Medicine, Dayton, Ohio, USA
}

\begin{abstract}
Splenic infarct (SI) is a rare clinical diagnosis typically characterized by symptoms of abdominal pain, nausea, and vomiting. Here we provide a unique case of SI, presenting as acute left-sided chest pain. This unusual presentation led us to incorrectly focus the initial investigation on diseases of cardiac origin. The resultant delay in correct diagnosis of Splenic Infarct and adequate treatment is described. This case highlights the need to consider SI in patients with acute chest pain, particularly in the presence of predisposing factors, such as hematological malignancy or autoimmune rheumatic diseases.
\end{abstract}

\section{Introduction}

Infarction of the spleen is a rare clinical event, with the annual incidence rate lower than $0.00999-0.0194 \%$ among the general population [1]. Splenic infarct (SI) is mostly associated with trauma or hematological disorders such as sickle cell disease, lymphoma, leukemia, and myelofibrosis [2]. Other less common predisposing factors are cardiac embolism in the setting of atrial fibrillation or infective endocarditis, and thrombosis under procoagulant status, such as systemic infection [1]. Another group of pathological entities closely associated with SI is autoimmune rheumatic diseases, notably systemic lupus erythematosus (SLE) and Granulomatosis with polyangitis (GPA) [3]. Clinicians should further investigate the fact that SI can be the first sign of underlying disease as early recognition and intervention could improve a patient's prognosis

Common symptoms of SI include abdominal pain, nausea, and vomiting. SI can also be accompanied by fever, leukocytosis, elevated levels of $\mathrm{LDH}$, or thrombophilia [4]. Patients with SI also may present in hemorrhagic shock from massive subscapular bleeding in the spleen [5]. Herein, we provide a unique case of SI, atypically presenting as acute left-sided chest pain that posed a true diagnostic challenge.

\section{Case report}

A 25-year-old man with a history of systemic lupus erythematosus (SLE) and end stage renal disease (ESRD) presented to the emergency department with an acute left-sided chest pain that began two hours earlier. The patient described the pain as sharp and persistent that radiated to his left shoulder and upper arm. He reported having cold sweats in association with the chest pain, but denied dyspnea or nausea. On physical examination, his blood pressure, heart rate, respiratory rate, temperature, and oxygen saturation at room temperature were 207/119 $\mathrm{mmHg}, 109 / \mathrm{min}, 18 / \mathrm{min}, 98.2{ }^{\circ} \mathrm{F}$, and $98 \%$, respectively. Except for hypertension, tachycardia, and tachypnea, no other abnormal findings were noted on physical exam. His ECG revealed sinus rhythm and cardiac enzymes were normal. Ultrasound and X-ray of the chest did not show abnormal findings. Contrast-enhanced CT of chest, abdomen, and pelvis revealed splenic infarct with extensive vascular calcifications within the splenic artery (Figure 1). The patient gradually improved on treatment with continuous heparin infusion at

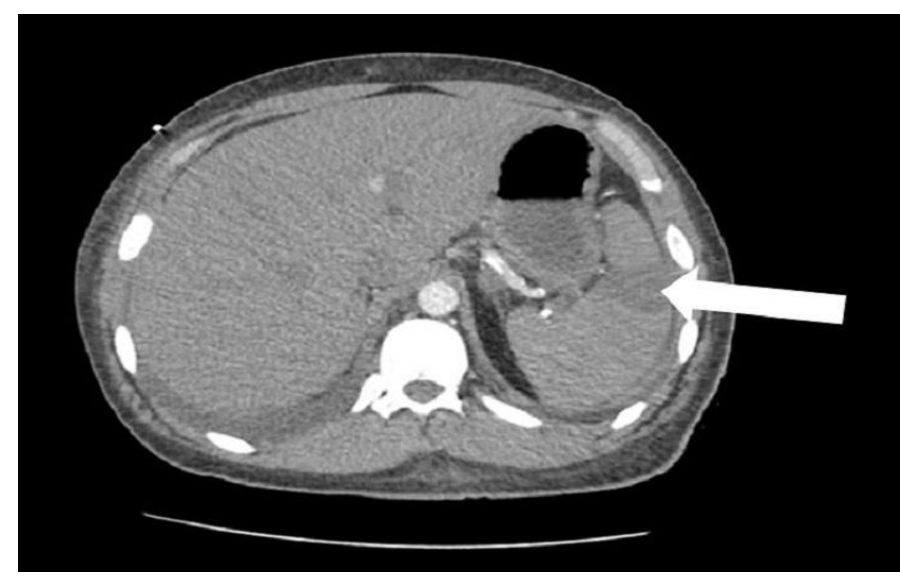

Figure 1. Splenic infarction (arrow) on axial section of contrast enhanced computed tomography of abdomen.

a rate of 1,700 to 2,700 units/hr. On the third day of hospitalization he was switched from heparin to apixaban, and afterward he was discharged.

\section{Discussion}

Splenic infarction (SI) occurs mostly in individuals with the aforementioned predisposing factors. Untreated, splenic infarct can result in the development of splenic abscess or pseudocyst, or it may cause hemorrhage with subsequent splenic rupture [6]. Thus, it is important for clinicians to maintain a high index of suspicion for splenic infarct in patients with diseases known to be associated with this complication who present with unexplained chest pain.

Correspondence to: Stella Pak, Department of Medicine, Kettering Medical Center, Kettering, Ohio, USA, Tel: (937) 298-4331, E-mail: Stella.Pak@ ketteringhealth.org

Key words: Splenic infarct, chest pain, systemic lupus erythematosus

Received: October 28, 2017; Accepted: November 27, 2017; Published: November 30, 2017 
In our patient, systemic lupus erythematosus (SLE) and end stage renal disease (ESRD) were most likely to have contributed to the development of SI. SI in patients with SLE is mostly caused by arterial thrombosis, promoted by autoantibody-induced endothelial injury $[3,7]$. Elevated levels of proinflammatory cytokines and chemokines also facilitates the thrombotic process [8]. As a result, the lifetime incidence rate of thrombosis among patients with SLE is estimated to be $9-37 \%$. Prothrombotic diathesis tends to be stronger in patients with longer disease duration [9]. Thrombotic events typically occur in circulation involving the brain, eyes, and distal arms and legs. SLE-induced thromboses however, rarely involve the splanchnic circulation [10].

Uremic bleeding tendency is a well-established complication from end-stage-renal disease (ESRD). Nonetheless, patients with ESRD are 5.6 times more likely to develop venous thrombosis than the general population. Along the same line, arterial thrombosis is 8.4 - 11.9 times more common among patients with ESRD compared to the general population [11]. Increased level of oxidative stress in ESRD patients causes extensive endothelial injury. ESRD is also associated with absolute protein $\mathrm{S}$ deficiency and functional protein $\mathrm{C}$ deficiency. ESRD patients also tend to have high level of tumor necrosis factor- $\alpha$ (TNF- $\alpha$ ), interleukin-6 (IL-6), C-reactive protein (CRP), and fibrinogen. The elevated concentrations of all these proinflammatory cytokines and acute phase reactants suggest that ESRD involves systemic inflammation. Systemic inflammation favors the pro-thrombotic over anti-thrombotic cascades [12].

Initially diagnosing SI can prove to be a tough task as the lack of pathognomonic biomarker poses a great challenge to diagnosis. However, there are various imaging modalities that aid clinical investigation. In sonographic imaging, acute SI appears as a peripheral wedge hypoechoic lesion [13]. Computerized tomography (CT) with contrast is preferred over sonography due to better resolution of splenic lesions. On CT scan, SI is shown as a segmental wedge-shaped area with low attenuation. Other modes of imaging capable of visualizing SI include magnetic resonance imaging (MRI) and scintigraphy [14]. Owning to the rarity of SI, there is no sufficient evidence yet to assess sensitivity and specificity of various imaging modalities for SI.

The centerpiece of SI management consists of supportive therapy, such as intravenous hydration, blood transfusion, and analgesia when necessary. Patients with symptoms refractive to conservative treatment generally undergo splenectomy. Close monitoring with focus on cardiovascular status is critical in early detection and intervention of known complications of SI, which include the following: splenic rupture, hemorrhage, abscess, or pseudocyst [15-20]. Treatment specific to underlying etiology for SI is also of paramount importance. Infectious diseases known to be associated with SI also warrant proper treatment, these include infectious mononucleosis, malaria, and babesiosis [21-23].

For patients with SI secondary to arterial or venous thrombosis, anticoagulation therapy with heparin or warfarin, thrombolytic treatment, percutaneous or mechanical thrombectomy can be used [16-18]. Therapeutic apheresis, such as erythrocytapheresis and leukocytapheresis, has been commonly used for vaso-occlusive episode secondary to sickle cell diseases or hematologic malignancy [19-20].

\section{Conclusion}

In summary, this report describes atypical presentation of SI as chest pain. To the best of our knowledge there is only one other case that reported splenic infarct presenting as chest pain [24]. By reporting this case, we hope to raise the awareness of this often-over-looked complication by health care providers.

\section{References}

1. Caremani M, Occhini U, Caremani A, Tacconi D, Lapini L, et al. (2013) Focal splenic lesions: US findings. J Ultrasound 16: 65-74. [Crossref]

2. Kumar S, Gupta N, Singh NP, Walson S (2006) Multiple Splenic Infarcts in a Patient of Dilated Cardiomyopathy: An unusual Aetiology. J Indian Acad Clin Med 7: 239-242.

3. Fishman D, Isenberg DA (1997) Splenic involvement in rheumatic diseases. Semin Arthritis Rheum 27: 141-155. [Crossref]

4. Lawrence YR, Pokroy R, Berlowitz D, Aharoni D, Hain D, et al. (2010) Splenic infarction: an update on William Osler's observations. Isr Med Assoc J 12: 362-365. [Crossref]

5. Ozakin E, Cetinkaya O, Baloglu Kaya F, Acar N, Cevik AA (2016) A Rare Cause of Acute Abdominal Pain: Splenic Infarct (Case Series). Turk J Emerg Med 15: 96-99. [Crossref]

6. Beeson MS (1996) Splenic infarct presenting as acute abdominal pain in an older patient. J Emerg Med 14: 319-322. [Crossref]

7. Bazzan M, Vaccarino A, Marletto F (2015) Systemic lupus erythematosus and thrombosis. Thromb J 13: 16. [Crossref]

8. Frieri M (2012) Accelerated atherosclerosis in systemic lupus erythematosus: role of proinflammatory cytokines and therapeutic approaches. Curr Allergy Asthma Rep 12: 25-32.

9. Burgos PI, Alarcón GS (2009) Thrombosis in systemic lupus erythematosus: risk and protection. Expert Rev Cardiovasc Ther 7: 1541-1549. [Crossref]

10. Arnold MH, Schrieber L (1988) Splenic and renal infarction in systemic lupus erythematosus: association with anti-cardiolipin antibodies. Clin Rheumatol 7: 406410

11. Ocak G, Vossen CY, Rotmans JI, Lijfering WM, Rosendaal FR, et al. (2011) Venous and arterial thrombosis in dialysis patients. Thromb Haemost 106: 1046-1052. [Crossref]

12. Casserly LF, Dember LM (2003) Thrombosis in end-stage renal disease. Semin Dial 16: 245-256. [Crossref]

13. Llewellyn ME, Jeffrey RB, DiMaio MA, Olcott EW (2014) The sonographic "bright band sign" of splenic infarction. J Ultrasound Med 33: 929-938. [Crossref]

14. Gupta S, Kakar A (2004) Splenic Infarct of Unusual Aetiology. J Indian Acad Clin Med 5: 310-314.

15. Al-Salem AH (2013) Massive splenic infarction in children with sickle cell anemia and the role of splenectomy. Pediatr Surg Int 29: 281-285. [Crossref]

16. Phillips DR, Conley PB, Sinha U, Andre P (2005) Therapeutic approaches in arterial thrombosis. J Thromb Haemost 3: 1577-1589. [Crossref]

17. Wakefield TW (2000) Treatment options for venous thrombosis. J Vasc Surg 31: 613 620. [Crossref]

18. Morgan R, Belli AM (2002) Percutaneous thrombectomy: a review. Eur Radiol 12 205-217. [Crossref]

19. Ullrich H, Fischer R, Grosse R, Kordes U, Schubert C, et al. (2008) Erythrocytapheresis: Do Not Forget a Useful Therapy!. Transfus Med Hemother 35: 24-30. [Crossref]

20. Hölig K, Moog R (2012) Leukocyte Depletion by Therapeutic Leukocytapheresis in Patients with Leukemia. Transfus Med Hemother 39: 241-245.

21. Naviglio S, Abate MV, Chinello M, Ventura A (2016) Splenic Infarction in Acute Infectious Mononucleosis. J Emerg Med 50: e11-13. [Crossref]

22. Florescu D, Sordillo PP, Glyptis A, Zlatanic E, Smith B, et al. (2008) Splenic infarction in human babesiosis: two cases and discussion. Clin Infect Dis 46: e8-11. [Crossref]

23. Hwang JH, Lee CS (2014) Malaria-induced splenic infarction. Am J Trop Med Hyg 91: 1094-1100. [Crossref]

24. Koyuncu M, Köstekci SK, Öztürk D, Ekinci N (2015) Splenic Infarction as a Rare Cause of Chest Pain. Eurasian J Emerg Med 14: 154-156.

Copyright: (C2017 Pak S. This is an open-access article distributed under the terms of the Creative Commons Attribution License, which permits unrestricted use, distribution, and reproduction in any medium, provided the original author and source are credited. 